\title{
THE EFFECT OF BIOCERAMIC SEALERS ON THE FRACTURE RESISTANCE OF ENDODONTICALLY TREATED TEETH (IN VITRO STUDY)
}

\author{
Medhat Taha Elfaramawy* and Tariq Yehia Abdelrahman*
}

\begin{abstract}
This study aimed to evaluate the effect of bioceramic sealers on the fracture resistance of endodontically treated teeth compared to resin-based sealers and zinc oxide and eugenol based sealers.
\end{abstract}

Methods: Seventy $(n=70)$ freshly human extracted single rooted teeth were selected. The samples were biomechanically prepared and classified according to the type of the sealer used into four groups as follows; Group $1(\mathrm{n}=21)$ obturated with gutta-percha and Endofill sealer (Dentsply, Germany). Group $2(\mathrm{n}=21$ ) obturated with gutta-percha and AD-seal sealer (Meta Biomed, Korea). Group 3 ( $n=21$ ) obturated with gutta-percha and MTA filapex sealer (Angelus, Brazil). Group 4 $(n=7)$ Control group (unobturated). All samples were kept in saline until evaluation. The samples were further classified according to the observation time into: subgroup A ( $n=7)$ evaluated after one week, subgroup B $(n=7)$ evaluated after two weeks and subgroup $C(n=7)$ evaluated after one month. Samples were loaded vertically after obturation using Universal Testing Machine until fracture.

Results: MTA filapex group showed higher fracture resistance values than the other groups with no significant difference. No significant difference was found between the subgroups evaluated at different time intervals.

Conclusion: Neither the type of root canal sealer nor the time lapsed affects fracture resistance significantly.

KEYWORDS: fracture resistance, resin-based sealer, bioceramic sealers, MTA filapex.

\section{INTRODUCTION}

The main problem of endodontically treated teeth is its high susceptibility to vertical root fracture $^{(1,2)}$. This is related to multiple factors such as previous weakening by extensive caries, access cavity preparation, biomechanical preparation with different irrigants and intracanal medicaments. Many attempts have been done to reinforce teeth after root canal treatment by taking benefits of bioceramics. However, the effect of sealers on fracture resistance of endodontically treated teeth is debatable. A critical review by Kim et al (3)

\footnotetext{
* Endodontic Dep., Faculty of dentistry, AinShams Univ.
} 
concluded that adhesive procedures of methacrylate resin based sealers were not able to strengthen dentin after root canal treatment, while a systematic review done by Uzunoglu-Özyürek ${ }^{(4)}$ concluded that root canal sealers increased fracture resistance of endodontically treated teeth. The purpose of this study was to compare fracture resistance of roots after obturation with gutta-percha and Endofil, Adseal, and MTA-Fillapex sealers.

\section{MATERIALS AND METHODS}

Seventy extracted human single rooted teeth with no signs of internal or external resorption were used. Teeth were decoronated using diamond disc mounted in a low speed hand piece under water coolant to standardize roots length at $13 \mathrm{~mm}$. Size 10 $K$ file was used to assure patency of the canal and the apical foramen. The working length was established by subtracting $1 \mathrm{~mm}$ from the length obtained when the file tip just appeared at the apical foramen. Root canals were instrumented using ProTaper Universal rotary files (Dentsply, Maillefer, Switzerland) up to F4. Irrigation was made with $2.5 \% \mathrm{NaOCl}$ (Clorox, Egypt) during the instrumentation. At the end of the preparation, the smear layer was removed by irrigation with $10 \mathrm{ml}$. of $17 \%$ EDTA(Meta Biomed, Korea), then final rinse with $3 \mathrm{ml}$ of saline (Novartis, Egypt) was performed.

The samples were classified according to the type of the sealer used into four groups as follows; Group $1(n=21)$ obturated with gutta-percha and Endofill sealer (Dentsply, Germany). Group $2 \quad(n=21)$ obturated with gutta-percha and AD-seal sealer (Meta Biomed, Korea). Group 3 ( $n=21)$ obturated with gutta-percha and MTA filapex sealer (Angelus, Brazil). Group $4(\mathrm{n}=7)$ Control group (unobturated).

Roots were obturated with lateral compaction technique using master cone size 40 taper $4 \%$. Each sealer was prepared \& used according to manufacturer's instructions. Quality of obturation was confirmed radiographically, where specimens containing voids have been excluded. All roots were kept in $100 \%$ humidity at $37^{\circ} \mathrm{C}$ for 24 hours to ensure complete setting of sealers. Roots were covered with silicon-based impression material up to $4 \mathrm{~mm}$ apical to the coronal margin to simulate periodontal ligaments. The samples were further classified according to the observation time into: subgroup A $(n=7)$ evaluated after one week, subgroup $B(n=7)$ evaluated after two weeks, and subgroup $\mathrm{C}(\mathrm{n}=7)$ evaluated after one month. Samples were mounted using disposable plastic syringes $(10 \mathrm{~mm}$.) where self cured acrylic resin was mixed and applied in the plastic syringes and the samples were placed in perpendicular direction in the acrylic resin with 3-4 $\mathrm{mm}$. of the coronal part of the samples were exposed. The acrylic blocks including the samples were mounted on the lower fixed compartment of Instron testing machine (Model 3345, England) with a load cell of $5 \mathrm{KN}$ and then secured by tightening screws. A cylindrical steel rod with round tip 2 $\mathrm{mm}$ in diameter attached to the upper part of the universal testing machine was used to apply force on the root at a crosshead speed of $1 \mathrm{~mm} / \mathrm{min}$ until fracture occurred. The load of failure was defined by an audible crack and confirmed by sharp drop at load deflection curve recorded using computer software in Newtons.

Data were analyzed by SPSS software (version 16.0, SPSS, USA). Data in each group were compared by the ANOVA and Kruskal-Wallis tests. Also the Dunnett's test was performed to compare the results between two groups. The level of significance was set at 0.05 .

\section{RESULTS}

Mean and Standard deviation (SD) values for intergroup comparison of fracture resistance values were presented in table (1) and figure (1).

MTA filapex subgroup $\mathrm{C}$ showed the highest mean value (687 \pm 61 ), while Endofill subgroup C showed the least mean value $(583 \pm 67)$. Statistically, there was no significant difference between the three groups at different observation periods $(\mathrm{p}<0.05)$. 
TABLE (1) Descriptive statistics and comparison of fracture resistance between groups (ANOVA).

\begin{tabular}{|c|c|c|c|c|}
\hline Group & $\begin{array}{c}\text { Group 1 } \\
\text { (Endofill) }\end{array}$ & $\begin{array}{c}\text { Group 2 } \\
\text { (AD-seal) }\end{array}$ & $\begin{array}{c}\text { Group 3 } \\
\text { (MTA filapex) }\end{array}$ & Control \\
\hline Subgroup A (1 week) & $600 \pm 95^{\text {a }}$ & $640 \pm 57^{\text {a }}$ & $670 \pm 75^{\text {a }}$ & $579 \pm 69^{a}$ \\
\hline Subgroup B (2 weeks) & $590 \pm 102^{\text {a }}$ & $635 \pm 80^{a}$ & $685 \pm 80^{a}$ & \\
\hline Subgroup C (1 month) & $583 \pm 67^{a}$ & $645 \pm 73^{a}$ & $687 \pm 61^{\text {a }}$ & \\
\hline
\end{tabular}

Significance level $p<0.05$ (Kruskall Wallis: $P=.237$ )

Mean values with the same letter are insignificantly different

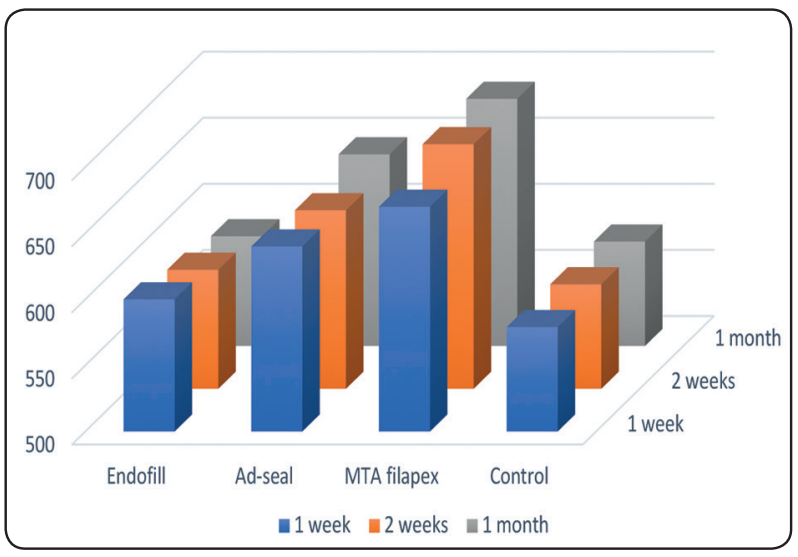

Fig. (1) Column chart showing mean fracture resistance $(\mathrm{N})$ in different subgroups.

\section{DISCUSSION}

Vertical root fracture (VRF) is a serious complication that can occur in up to $20 \%$ endodontically treated teeth that eventually ends with tooth extraction ${ }^{4}$. For measurement of fracture resistance of specimens, Instron testing machine was used. Vertical force was applied at $90^{\circ}$ angle to the decoronated roots until VRF occurred ${ }^{5}$. This testing technique is similar to the one used by Sedgley and Messer ${ }^{6}$ to test the brittleness of endodontically treated teeth. This technique was found to be more clinically relevant as it simulates the normal attachment apparatus of healthy tooth, with more homogenous stresses distribution and without stress build-up caused by unrealistic bending movements ${ }^{7}$.

In the present study, MTA filapex sealer had the highest mean value for fracture resistance followed by Ad-seal sealer then Endofill sealer, without statistically significant difference. Our results disagree with Sagsen et al ${ }^{8}$, Mandava et al ${ }^{9}$ and Mittal et al ${ }^{10}$ in which the resin-based sealer had the highest fracture reistance values in comparison with other sealers. They explained their results by the formation of a covalent bond between the open epoxide ring of the epoxy resin sealer and amino groups in the exposed collagen of the root canal dentin ${ }^{11}$. On the other hand, results of our study are consistent with Nagpal et al ${ }^{12}$ and Patil et al ${ }^{13}$, in which roots obturated with bioceramic sealers showed higher fracture resistance values than roots obturated with non-bioceramic sealers. This can be explained by the incorporation of $\mathrm{Ca}$ and $\mathrm{Si}$ in dentin with subsequent chemical, physical and structural modification of dentin, resulting in higher fracture resistance and strength ${ }^{14}$.

\section{CONCLUSIONS}

1. Neither the type of root canal sealer nor the timelapsed affects fracture resistance significantly.

2. Further tests are needed to evaluate the effect of different core obturating materials on fracture resistance of endodontically treated teeth. 


\section{REFERENCES}

1. Trope M, Ray HL. Resistance to fracture of endodontically treated roots. Oral Surg Oral Med Oral Pathol Oral Radiol Endod 1992;73:99-102.2.

2. Dang DA, Walton RE. Vertical root fracture and root distortion: effect of spreader design. J Endod 1989;15:294-301.

3. Kim YK, Grandini S, Ames JM, et al. Critical Review on Methacrylate Resin-based Root Canal Sealers. doi:10.1016/j.joen.2009.10.023

4. Uzunoglu-Özyürek E, Küçükkaya Eren S, Karahan S. Effect of root canal sealers on the fracture resistance of endodontically treated teeth: a systematic review of in vitro studies. Clin Oral Investig. 2018;22(7):2475-2485. doi:10.1007/s00784-018-2540-9

5. Ersoy I, Evcil MS. Evaluation of the effect of different root canal obturation techniques using two root canal sealers on the fracture resistance of endodontically treated roots. Microsc Res Tech. 2015;78(5):404-407. doi:10.1002/ jemt.22487

6. Sedgley CM, Messer HH. Are endodontically treated teeth more brittle? J Endod. 1992;18(7):332-335. doi:10.1016/ S0099-2399(06)80483-8

7. Phukan AH, Mathur S, Sandhu M, Sachdev V. The effect of different root canal sealers on the fracture resistance of endodontically treated teeth-in vitro study. Dent Res J (Isfahan). 14(6):382-388.

8. Sagsen B, Er O, Kahraman Y, Akdogan G. Resistance to fracture of roots filled with three different techniques.
Int Endod J. 2007;40(1):31-35 . doi:10.1111/j.13652591.2006.01177.x

9. Mandava J, Chang P, Roopesh B, Faruddin M, Anupreeta A, Uma C. Comparative evaluation of fracture resistance of root dentin to resin sealers and a MTA sealer: An in vitro study. J Conserv Dent. 2014;17(1):53. doi:10.4103/09720707.124140

10. Mittal A, Dadu S, Garg P, Yendrembam B, Abraham A, Singh $\mathrm{K}$. Comparative evaluation of fracture resistance of endodontically treated teeth with epoxy resin-based sealers ah plus and mineral trioxide aggregate fillapex: An in vitro study. Indian J Dent Sci. 2017;9(1):8.doi:10.4103/IJDS.IJDS_83_16

11. Chadha R, Taneja S, Kumar M, Sharma M.An in vitro comparative evaluation of fracture resistance of endodontically treated teeth obturated with different materials. Contemp Clin Dent. 2010;1(2):70. doi:10.4103/0976-237X.68590

12. Nagpal A, Annapoorna BM, Prashanth MB, et al. A Comparative Evaluation of the Vertical Root Fracture Resistance of Endodontically Treated Teeth The Journal of Contemporary Dental Practice. 13(3):351-355. doi:10.5005/ jp-journals-10024-1150

13. Patil P, Banga K, Pawar A, Pimple S, Ganeshan R. Influence of root canal obturation using gutta-percha with three different sealers on root reinforcement of endodontically treated teeth. An in vitro comparative study of mandibular incisors. J Conserv Dent. 2017;20(4):241. doi:10.4103/ JCD.JCD_233_16

14. Viegas OG. Analysis of the Interface between calcium silicate-based endodontic materials and root canal dentine: a pilot study. 2013 . 